\title{
The role of emergent structure in Conceptual Blending Theory - case studies of children in advertisements
}

\begin{abstract}
The aim of this article is to consider the role of emergent structure in conceptual integration networks and the impact it has on the process of meaning construction. What is under analysis is the way in which a well-established emergent structure helps the blend to achieve its goals of providing human scale and achieving its persuasive effects. The analysis is a case study of four advertising campaigns which use conceptual blending to advertise their products via manipulating an image of a child into their advertising posters.
\end{abstract}

Key words: Cognitive Linguistics, mental spaces, conceptual blending theory, emergent structure, persuasive effects.

\subsection{Introduction}

The aim of this article is to present basic principles governing the process of conceptual blending as employed in the advertising campaigns using images of children in achieving particular persuasive effects, with a special focus on emergent structure: its place within the whole integration network, its creation, development and elaboration, as well as its impact on the interpretation of the input spaces contained in the network.

The main purpose of the analysis is to prove the unique status of emergent structure as a feature specific to Conceptual Blending Theory $(1995,1998,2000,2002)$, as well as to provide evidence for the claim that emergent structure is crucial for explaining inferences arising from the integration of two or more conceptual inputs, which are not directly available from the inputs analyzed in isolation. Emergent structure is treated as a result of the creative online processing of projections of elements from input mental spaces onto a newly established space, the blend.

The first part of this article provides a brief analysis of the mechanism of blending, with a special emphasis on the role of the projection of elements and inferences to establish a coherent and internally integrated network of mental spaces. Then follows a detailed account of emergent structure as the result of the said projections. What is explained in detail are the subsequent stages via 
which the emergent structure is created, i.e. composition, completion and elaboration of the blend. Then the article focuses briefly on the processes which strengthen the internal congruity of the blend, i.e. compression of vital relations and backward projection of inferences from the blend back onto the input spaces, as mechanisms which are exceptionally effective in providing a human scale, and reevaluation of the frames contained in the inputs.

The first part of the article provides a theoretical background for further analysis of selected examples of visual blends included in later sections. It explains the main notions, mechanisms and terms necessary for the efficient description of processes involved in the creation of the emergent structure, as well as its development and, finally, its effects.

\subsection{Method and database}

The corpus consists of ten posters collected from four advertizing campaigns, two of which use the image of a child to advertise a notion directly involving children - candies in "Chupa Chups. It's the end of the world without it", and adoption in "Adopt. You can receive more than you can ever give" - and two to advertise products not directly related to the conceptual domain of children a bank, in "Sofia Bank. Experienced, although newborn", and car tires in "Michelin. Because so much is riding on our tires". Four of the posters are analyzed in this article.

The analysis is based on the application of Conceptual Blending Theory, as developed by Gilles Fauconnier and Mark Turner (1995, 1998, 2000, 2002). It also follows Joy et al.'s observations of conceptual blending as being a process of arrival at the meaning of advertisements with a dose of individuality between the viewers since the process of meaning construction depends on the individual "activation, interconnection and manipulation of mental spaces" (2009: 48). It is also crucial to note their observation that "an awareness of cross-cultural understandings" is crucial for correct deciphering various advertisements (ibid.).

Also, since blending is a conceptual process of meaning construction, it is assumed in this article that it may be found in its nonverbal manifestations, much like metaphor in Forceville's work on advertisements (1994).

\subsection{General characteristics of the mechanism of blending}

As Fauconnier and Turner (1995) point out, Conceptual Blending is a process of on-line meaning construction based on the integration of at least four conceptual structures into a dynamic network which stays strongly dependent on context. Since the process is local and dynamic, the structures used in the integration are mental spaces, which are local meaning constructions, rather than conceptual domains which are whole systematically structured areas of knowledge. The process of integration is based on the projection of elements across mental spaces involved in the network: two input mental spaces, a generic space and a blended space. The cross-space mapping which connects counterpart elements contained within the input spaces gives rise to newly emerged inferences and judgments which are not directly available from any of the inputs considered separately. These inferences are contained within 
a newly established mental space, the blend, which remains systematically connected to the inputs (see Fauconnier 2005: 525). Crucially, the blend, apart from being only a collection of mappings from the input spaces, contains a structure which is not predictable from any of the mental spaces involved in the meaning construction process (see Fauconnier and Turner 1995). The structure emerges as a result of all the projections involved in the network and provides a unique logic to the blend. The whole process of conceptual integration may be schematically represented in a diagram proposed by Fauconnier and Turner (2002: 46), Figure 1.

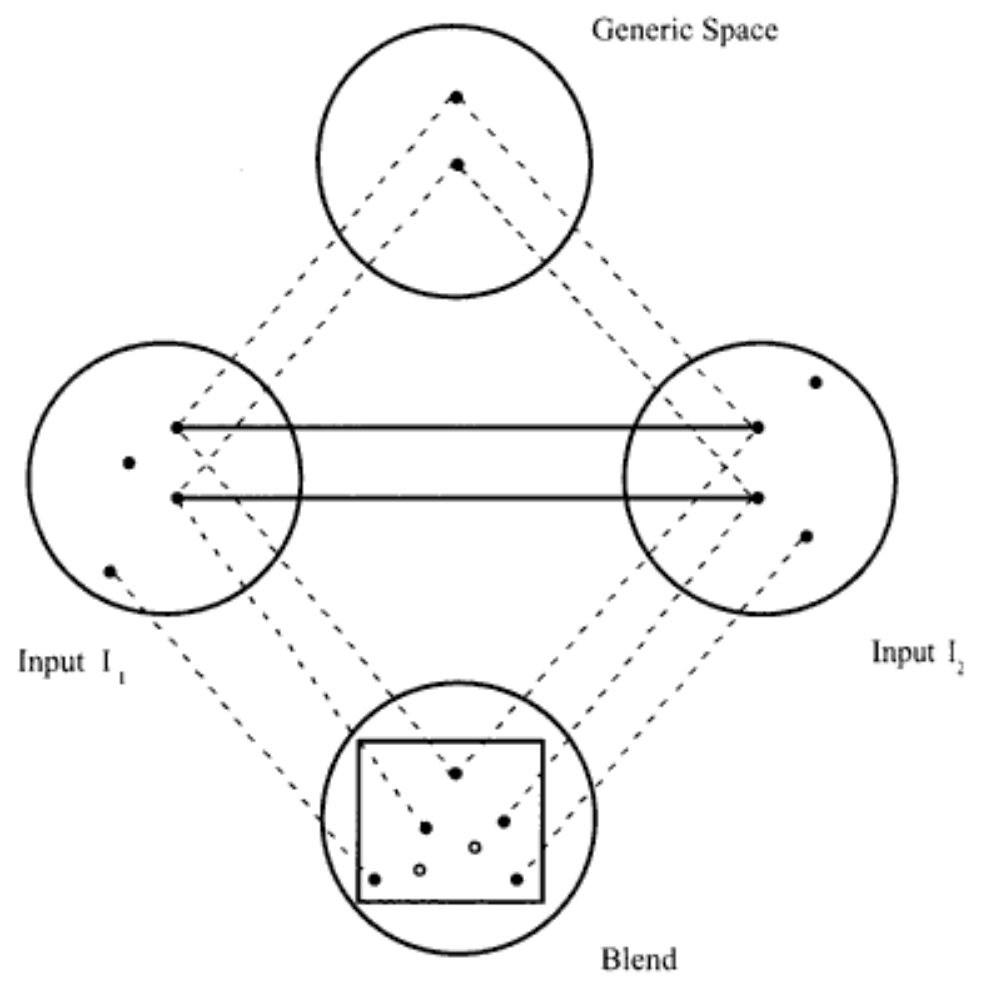

Figure 1. Mechanism of blending

The circles in the diagram represent mental spaces, the dotted lines symbolize projections between elements across the whole integration network, the solid lines indicate mappings between counterpart elements between two input spaces, whereas the square within the blend represents the emergent structure (see Fauconnier and Turner 2002: 46f). The generic space comprises highly schematic features characteristic of both of the inputs. It facilitates the process of establishing the cross-space mappings between counterpart elements from the input mental spaces. In this way, it can be further projected onto the blend (see Evans and Green 2006: 406). It is important to note that while the generic space contains only the elements common to both of the inputs, the blended space with its emergent structure is composed not only of the elements projected selectively from the input spaces and counterpart elements found in the generic space, but also contains elements not present in any of the input spaces (see Fauconnier and Turner 2002: 46f). 


\subsection{An insight into the emergent structure}

The possibility of arriving at the emergent structure is the factor that distinguishes Conceptual Blending Theory from other cognitive processes of meaning construction. The discovery of emergent structure enabled linguists to explain a novel meaning of utterances which was not derived directly from any of the input structures, either linguistic or conceptual, involved in the meaning construction process (see Evans and Green 2006: 401).

The blend's emergent structure may generate the meaning of sentences whose meaning often cannot be solved by the conceptual metaphor approach, such as "This surgeon is a butcher" (see Kövecses 2006: 275). The negative assessment of the surgeon as being incompetent comes about not as a result of a simple mapping of meaning from the domain of butchery onto the domain of medical craftsmanship, but instead emerges as a new concept of a surgeon who, while performing an operation, uses the skills of a butcher, which as a result renders him incompetent (see Kövecses 2006: 275ff, see also Brandt and Brandt 2005). It is important to note that such a composition of a surgeon possessing the skills of a butcher did not appear in any of the input structures.

The emergent structure arises as the result of multiple projections of elements from input mental spaces onto the blended space. These projections give rise to new inferences, which can be later projected back onto the inputs. Since the projections are multidirectional, the blended space with its emergent structure remains constantly linked to the whole integration network (see Fauconnier and Turner 1998: 305).

\subsection{Creation of the emergent structure}

The emergent structure arises as a result of three operations performed during the construction of the blend. These operations are: composition, completion and elaboration.

Composition is based on the selective projection of elements from the input spaces onto the newly established mental space, the blend. Counterparts from the inputs are mapped onto the blend either as separate items or projected into one element. The latter type of projection is referred to as fusion. Composition creates new relations between mental spaces involved in the integration networks, thus that operation is often sufficient for the emergent structure to arise (see Fauconnier and Turner 2002: 48).

Completion recruits well entrenched background knowledge about elements composed into the blend. It completes the structure of the blend with other structures and scenarios employed from background everyday experience. The most basic form of recruitment is pattern completion, thanks to which, as Fauconnier and Turner suggest, "[a] minimal composition in the blend can be extensively completed by a larger conventional pattern" (1998: 315). It is also interesting to note the metonymic character of this process. Elements projected from the input spaces into the blend serve as vehicles for the recruitment of much broader knowledge originating from the cognitive domain of which they were part (here: the part for whole conceptual metonymy) or other non-counterpart elements which were not originally in the inputs but become part of the blend (ibid.: 336). 
Elaboration develops the blend further by imaginative mental simulation performed in accordance with the newly established logic and principles which emerged during the composition and completion of the blend. Further "running the blend" may lead to the emergence of yet other new principles and logic used for subsequent simulation (see Fauconnier and Turner 1998: 315). The elaboration of the blend may be performed indefinitely, since mental simulation is performed via imaginative use of all the elements and logics incorporated within the blend. Creating new inferences or introducing new concepts to the blend lead to its further elaboration (see Fauconnier and Turner 2002: 49).

All these operations lead to the creation of an emergent structure in the whole integration network (ibid.). As Evans and Green point out, "[t]he structure is 'emergent' because it emerges from 'adding together' structure from the inputs to produce an entity unique to the blend" (2006: 405). The inferences created by running the blend provide a novel structure which enables operations otherwise impossible in any of the input spaces (see Fauconnier 2005: 528). Since the process of conceptual integration is on-line and non-algorithmic (see Fauconnier and Turner 1998: 306), the imaginative act may be performed at any site of the network in order to achieve a satisfactory integration (see Turner 2007: 22).

\subsection{Compression and human scale}

Apart from providing explanations for novel meanings emerging from the unconventional use of linguistic expressions, Conceptual Blending, being a cognitive process, provides much broader effects to human cognition. As Evans and Green point out, the main purpose of blending is to provide global insight, i.e. to present new or already existing ideas in the most understandable way (see 2006: 418). Fauconnier and Turner claim that blends, by arriving at global insight, achieve a human scale which, as the authors argue, is the most crucial principle governing conceptual integration (see 1998: 339).

Human scale is obtained by the simplification of complex notions, i.e. reducing complexity to the scope of the basic human experience (see Fauconnier and Turner 2002: 30). According to Fauconnier and Turner, this process is guided by a number of sub-goals in the blend construction (1998: 339). Among such processes are, for instance, compression and intensification of vital relations shared by the input spaces into the vital relations present in the blend (see Turner 2006: 17; for the full list of such sub-goals, see Fauconnier and Turner 1998: 340, or Evans and Green 2006: 419).

Compression seems to be one of the most crucial elements in the construction of the blend and seems to provide the most powerful effects. Turner defines compression as "transforming diffuse and distended conceptual structures that are less congenial to human understanding so that they become more congenial to human understanding, better suited to our human-scale ways of thinking" (see 2006: 18, for more about compression and vital relations see also Fauconnier and Turner 2000: 283-304). In other words, via compression, the blend not only gains a new unique structure obtained by compressing elements and relations from input mental spaces, but also becomes more immediate to human attention. 
Projection of vital relations and their compressions within the blended space has a crucial effect on the topology of the blend and its emergent structure. Fauconnier and Turner (see 1998: 343 355) provide a comprehensive classification of integration networks in accordance to the topological structure of the blend. They claim that four-space blends form shared topology networks, i.e. the topology of the generic space is projected onto all spaces involved in the integration. The difference in the organization of the blended space and thus its emergent structure is crucial. If the blended space inherits the organizing frame of one of the inputs, i.e. if one of the inputs provides the logic and structure for the blend to organize the elements projected from the other input, this network is single-scope. If, however, the blend is organized by the projections from both of the inputs and a new organized frame is thus created, the network is double-scope (for other types of networks, see Fauconnier and Turner 1998: 343-355). In each case, the result is the emergent structure which provides the blend with new inferences which are otherwise not available (see Turner 2006: 21). Fauconnier (see 2005: 530) and Turner (see 2006: 17) both claim that such integration of contrastive frames is basic and common to the human cognitive system.

Another crucial element of blending is backward projection. Since the projections in the integration network are multidirectional, certain properties developed in the blend are mapped backwards onto the input mental spaces. In other words, the emergent structure which arises through projections and compressions of diffuse concepts into coherent vital relations in the blend facilitates the interpretation of the notions presented in the input mental spaces (see Fauconnier 2005: 531f). In this way, the blend remains constantly linked with the whole integration network (see Fauconnier and Turner 1998: 310f).

\subsection{Cultural image of a child}

For the purpose of this article I assume a commonly shared image of a child present in western culture. I adopt a standardized viewpoint of an adult person and disregard any differences in perception connected with gender, race and economic or family status. In this cultural viewpoint I refer to, children are traditionally associated with positive attributes: they are innocent, active and eager to communicate, they have an excessively loving nature and exhibit positive naivety towards the world. Children are generally inexperienced but enthusiastically explore their surroundings, and they are happy, lovable and energetic. Adults perceive children as vulnerable; they also feel the need to provide them with affection, love, care and protection. There are, however, times when children bring slightly negative associations to mind: they tend to misbehave, often stubbornly insist on their whims, and are likely to overreact.

\subsection{It's the end of the world without}

\section{Chupa-Chups}

Children often have a tendency to overreact and misbehave, especially when something happens against their will or liking. The following advertisement, presented in Figure 2, seems to draw its inferences exactly from these characteristics. 


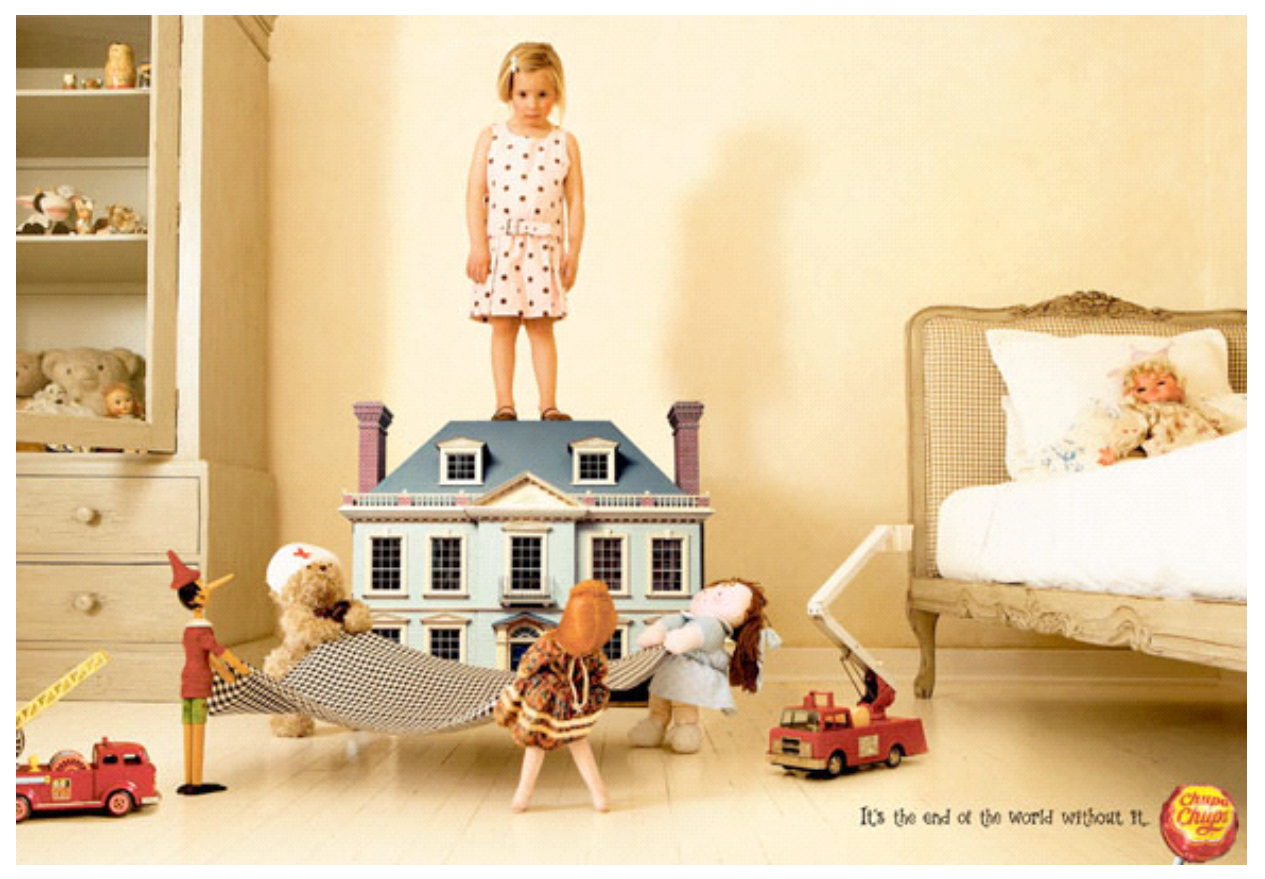

Figure 2. Chupa-Chups ad: a girl on a doll-house

The picture in Figure 2 presents one of the three advertising posters designed by an agency in South Africa for the Chupa-Chups brand in order to promote their lollipop candies. All three posters pictured children aged 4 to 8 in situations characteristic for adults suffering from severe depression: a boy lying on a sofa and talking to a teddy bear which is wearing a psychiatrist's lab coat, another boy sitting behind a bar, drinking glasses of milk, and a girl threatening to jump from a doll house. The last example is the subject of the analysis in this section.

As previously noted, the advertisement depicts an approximately 5-year-old girl standing on the rooftop of a doll house. She is looking reproachfully at the viewer. Considering her position, the arrangement of the toys below her, as well as the slogan of the campaign: "It's the end of the world without it", followed by the Chupa-Chups logo, the girl is evidently about to jump. Where does this interpretation of the scene come from? What was the cause of the girl's behavior? Does she really intend to jump? In order to address these questions, it is required to examine the situation more closely.

The advertisement makes use of conceptual blending in evoking its cognitive effects. The blend is composed of two input mental spaces: the first input is the mental space of SUICIDE, and the second input involves the child's grief, specifically after being denied her favorite candy. The mappings established between the inputs proceed as follows: a person about to commit suicide from the SUICIDE input corresponds to the girl who is overwhelmed with grief from the second input; the building from which the suicide victim is about to jump relates to the doll house; whereas the cause of the suicide corresponds to the lack of the Chupa-Chups lollipop. The generic space abstracted from the two input spaces consists in an individual overcome with tragedy to the point of not knowing how to continue their life any longer. 
The construction of the blended space proceeds as follows: the composition of the blend maps, the counterpart mappings from the input spaces, and the abstraction from the generic space onto the newly established element in the network, the blend. Some of the elements are fused together, i.e. forced under compression to form one entity within the blended space: the girl from the second input becomes the person about to commit suicide from the first input, the doll house becomes the building from which she is about to jump, and the lack of a lollipop becomes the cause of the forthcoming suicide. It is noticeable that one of the inputs, i.e. the mental space of sUICIDE, evidently provides an organizing frame for the input of the child's grief. Applying Fauconnier and Turner's classification of blends, this particular type of blending is described as a single-scope network, where the blended space is organized according to the logic projected from one of the inputs (1998: 343-355). The structure is completed by recruiting the background knowledge concerning suicide scenarios and behaviors characteristic to children when something goes against their will: their tendency to overdramatize, and emotional involvement. It is also interesting to note the metonymic character of the situation present in the picture: what the viewer is exposed to is the initial stage of a very concrete suicide scenario, i.e. jumping from the roof of a high building. The rest of the scenario is evoked automatically via the INITIAL STAGE OF THE ACTION FOR THE WHOLE ACTION conceptual metonymy.

Elaboration runs the blend as follows: the girl is so devastated about the lack of the ChupaChups candy that she does not know how to proceed with her life and hence consciously decides to end it. In order to do so, she has arranged her immediate surroundings which have been directly available to her. The cause of her misery is the overwhelming grief over being denied the most important thing in her life at this moment, which, judging by her disappointed straightforward look, was evidently induced by her parents or some other adult. Since the girl looks directly at the viewer of the advertisement, the viewer becomes fused with the parents or other adults who caused that reaction, and thus becomes directly involved in the scenario. Thanks to this technique, the advertisement obtains a number of powerful persuasive effects. Now it is the viewer who witnesses their daughter so devastated she decides to threaten her parents, or any other actual causers, to commit suicide. The viewer realizes that they have been the immediate cause of the situation by not giving the girl her favorite candy. What emerges is the direct feeling of guilt in the viewer because they have let such a situation happen. Instead of providing safety and care, they threaten the life of the ones they should protect. What is projected back is the intended message of the advertisement: what for an adult may seem a trivial matter, i.e. a simple Chupa-Chups lollipop, for a child is the equivalent of the meaning of life. Denying children their Chupa-Chups is like denying adults their reason to exist.

What is particularly striking in this advertisement is the emergent image of a child. In the emergent structure of this blend, the child inherits the reasoning and actions from the adult suicide input, i.e. the consciousness of the decision, knowledge about suicide scenarios, as well as the possible effects of blackmailing others by attempting to perform such an action. Interestingly, the child maintains her naivety: to commit her "suicide", the girl chooses a dollhouse instead of a real high 
building, which may provide a somewhat humorous effect. This juxtaposition of two strikingly different characteristics renders the advertisement powerful and effective and, thus successful.

\subsection{Adopt}

The previous advertisement used conceptual networks for strictly commercial purposes, i.e. its main goal was to present a product in the most effective way. However, conceptual blending is also equally persuasive in social advertising, where its primary function is raising awareness about a social phenomenon, in the case of the following example, about adoption.

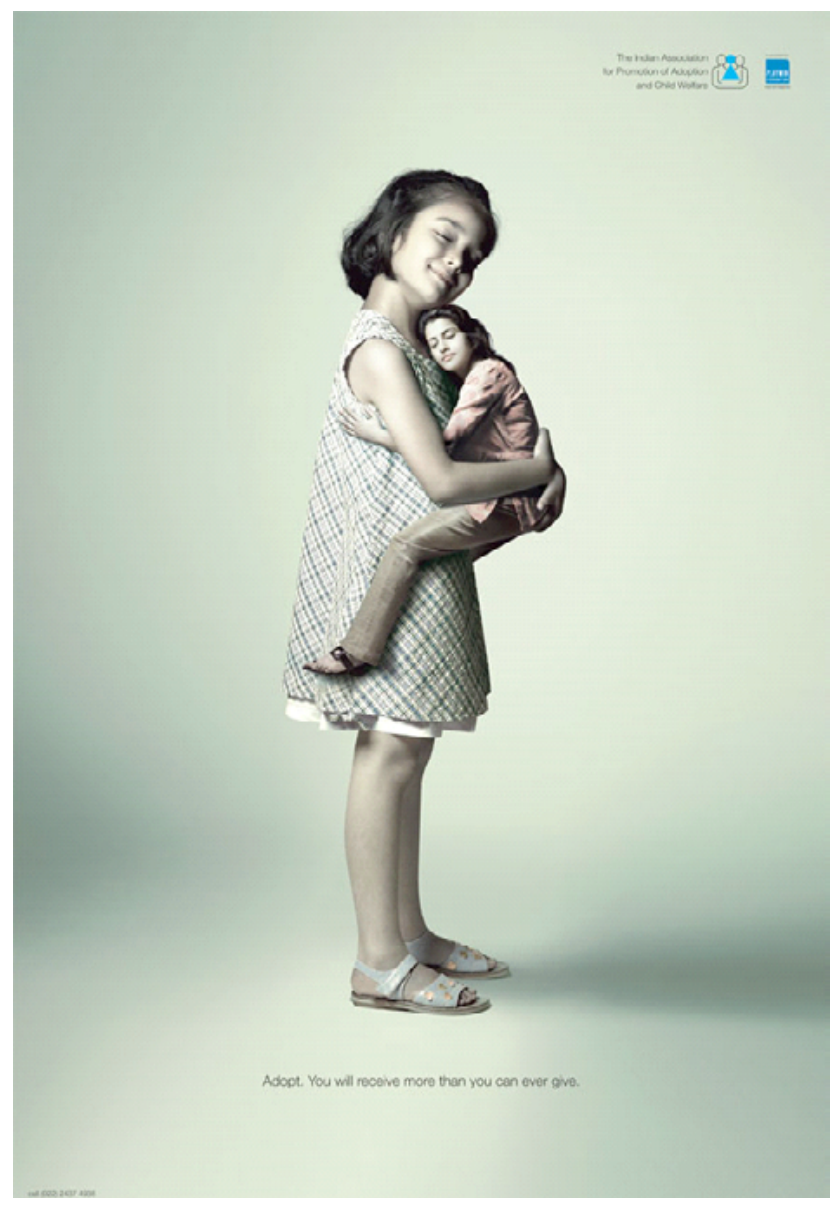

Figure 3. Adopt ad: a girl holding a woman

The advertisement presented in Figure 3 is part of an advertising campaign designed by The Indian Association for Promotion of Adoption and Child Welfare. SeeIt presents a mother and a daughter who are embracing each other. The headline at the bottom says: "Adopt. You will receive more than you can ever give". As already hinted, the advertisement uses conceptual blending in achieving its persuasive effects.

The integration network is composed of two inputs: a cognitive frame of KINSHIP with the specific roles of MOTHER and DAUGHTER, and another mental space containing an adult woman and a little girl who are not related to one another. Counterpart mappings connect the role of MOTHER 
with the woman and the DAUGHTER role with the girl. During the composition of the blend, the roles from frame of kinship and the elements from the second input are projected onto a newly created mental space, the blend. Pattern completion recruits additional background knowledge and scenarios about kinship, parenting and children into the blend, i.e. the ideas of providing protection, care and nurturing in the case of mothers: giving birth, and in the case of children: being the recipient of said care. However, once the viewer notices the physical arrangement of the woman and the girl on the poster, some new inferences come to light. The blend is elaborated in the following way: judging by the sizes of the girl and the woman, the girl is assigned a more prominent role. She stands straight and holds the woman as if she were her favorite toy. The shape they make together metonymically evokes the shape of a pregnant woman. However, what is striking is that it is not the woman who is pregnant but the girl. This shift in the internal structure of the blend, which is counterfactual, is enough to produce a powerful emergent structure. The vital relations of identity become reversed in the blend. In effect, the girl is assigned the role of the mother, i.e. she gives birth, provides love and nurturing for the woman, but still maintains her childlike figure. The woman, on the other hand, is assigned the recipient role of the child, i.e. she is the beneficiary of the girl's immense love and protection. In a way, it is the child who gives birth to the mother, and this inference is projected to reevaluate the inputs. Since the woman and the girl are not related to one another, and the girl is given the prominent status in their relationship, it is the existence of the girl which makes the woman a mother. This is when the adoption scenario is evoked. Since the woman is not able to conceive a child, adopting one makes her a mother, not only by having an opportunity to provide protection and care, but also by being immersed in the unconditional love of the child. In this sense, she receives more than she can give: apart from closeness and affection, she is given a chance to satisfy her inner need and desire, which she would never be able to fulfill by herself.

The image of the child evoked by the emergent structure of this blend only reinforces the characteristic features assigned to children in western culture. What is strengthened is the positive associations with children, such as their loving nature and their need to be taken care of. What is new and powerful in the blend is children's power to evoke positive feelings in the adult, or even to change their nature.

In both of the examples, presented in Figure 2 and Figure 3, the image of a child was used to advertise a notion directly connected with the conceptual domain of child, i.e. the Chupa-Chups poster advertised a candy: an element directly associated with children and their love for sweets, whereas the Adopt campaign focused on the family notion, of which children are an inseparable part. It is now necessary to posit a question: is there a possibility for the image of a child to be used to advertise a product or a notion which does not belong directly to the conceptual domain of children?

\subsection{The newborn experience}

The advertisement under analysis in this section uses conceptual networks to reason about an element which is not directly related to any of the input spaces involved in the creation of the blend it- 
self. The poster in Figure 4 is part of an advertising campaign for the Finnish Sofia Bank, whose aim was to promote the bank's refreshed image. The guiding slogan says: "Experienced, although newborn".

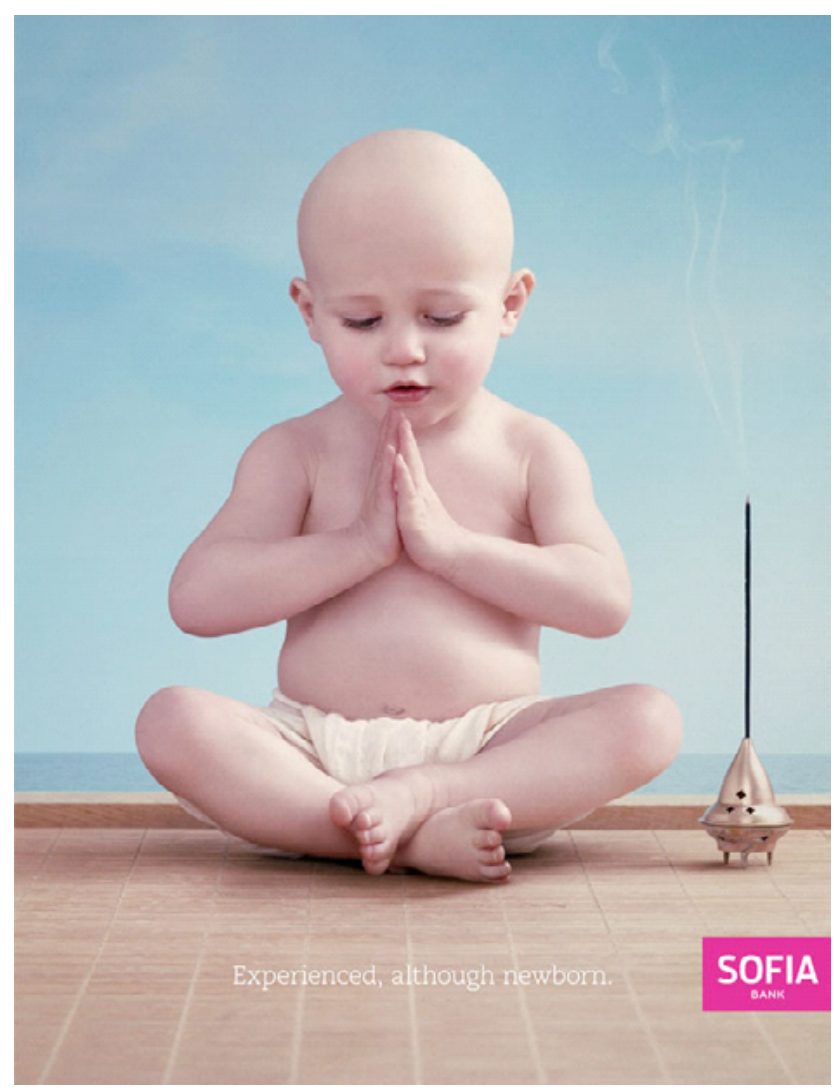

Figure 4. Sofia Bank ad: a baby meditating

The poster presents a newborn baby sitting in a lotus position, characteristic of advanced religious practices in Eastern Asia. The logo at the bottom introduces Sofia Bank. These three elements in fact serve as the inputs for creating the blend: a mental space of NEWBORN BABY, a mental space of MEDITATION, and a mental space of BANK. It is important to note the conceptual background knowledge which is evoked metonymically by both the baby and the position he sits in. Newborn babies are vulnerable, clumsy and generally inexperienced, whereas the meditative pose brings up rich knowledge from the cognitive frame of religious beliefs and practices in the Far East. Meditation is known as an advanced practice which not only requires a perfectly balanced body position, but also a well-trained mind. It is performed by individuals, often of high religious status, and requires practice, concentration and, above all, experience. What is also important to notice is that the BANK frame is evoked by the verbal Sofia Bank logo only. The logo's function is to anchor ${ }^{1}$ the whole reasoning about the baby and the meditation in the BANK mental space. What happens during the composition of the blend is fusing this inexperienced newborn baby into this highly experienced individual from the meditation input and then again fused with the bank from the

1 For more on anchoring, see Forceville 1994. 
BANK input. The Sofia Bank becomes thus personified. The vital relations of identity from all of the inputs become compressed into one entity in the blend - the baby. During completion, apart from recruiting the already mentioned background knowledge, what is also employed is the notion of experience, which is understood in much broader terms in the Eastern Asian area. In Eastern Asian religious beliefs, a hugely vivid notion is reincarnation, according to which after death a person's soul is reborn in a new body, hence advancing in the hierarchies of being. Thus, elaboration runs the blend and gives rise to an apparent emergent structure where the baby, although being newborn, possesses all the experience from his previous lives, and in this way, is able and competent to perform this highly advanced religious practice. The emergent structure gives rise to an internally contradictory image of a child being simultaneously new to the world and experienced within it. This compressed image is the most powerful effect of the blend. It is skillfully used further to reason about Sofia Bank, the object of the advertisement. In effect, the bank is like the newborn baby on the poster: it is fresh to the surroundings, easily adaptable, and eager to open itself up to the ever-changing market, yet still possesses its huge experience from its previous incarnations. Thanks to this experience the bank is likely to proceed in its existence, avoiding mistakes which would otherwise be bound to happen to any beginning banking institution.

It is crucial to note that the correct deciphering of the advertisement's meaning is only possible after the viewer recognizes the pose the baby sits in and connects it with the religious practices of the Far East. It not only proves that the cross-cultural awareness is essential to understand an advertisement, but also stresses the fact that the reading and elaboration of a blend are individualized processes and may differ from person to person, depending on their background knowledge.

The emerging image of the child in the "Experienced, although newborn" blend is used to advertise a notion which does not relate itself directly to the conceptual domain of children. Given a skillful manipulation of the elements within input spaces and the congruent emergent structure, the image of a child may serve as a very powerful tool of persuasion, especially in advertising. However, is it always effective to use blending to advertise a product?

\subsection{So much is riding on your tires}

All three advertisements discussed in the previous sections used conceptual blending in arriving at their powerful persuasive effects. In all of the examples the input spaces were readily recognized, the mappings were projected smoothly, and the emergent structure was congruent, efficient and effortless to follow. It provided coherent inferences which were later used to arrive at conclusive judgments about the products which were advertised. The image of a child used in these advertisements seemed to be a very effective means of persuasion, which would adapt itself to the particular needs of the companies freely.

In order to prove the necessity of an easy and effortless process of emergent structure formation and elaboration for the powerful persuasive effect of a blend, it is useful to consider an example of a less successful attempt at blending: an advertising poster designed for the Michelin tire company in Figure 5. 


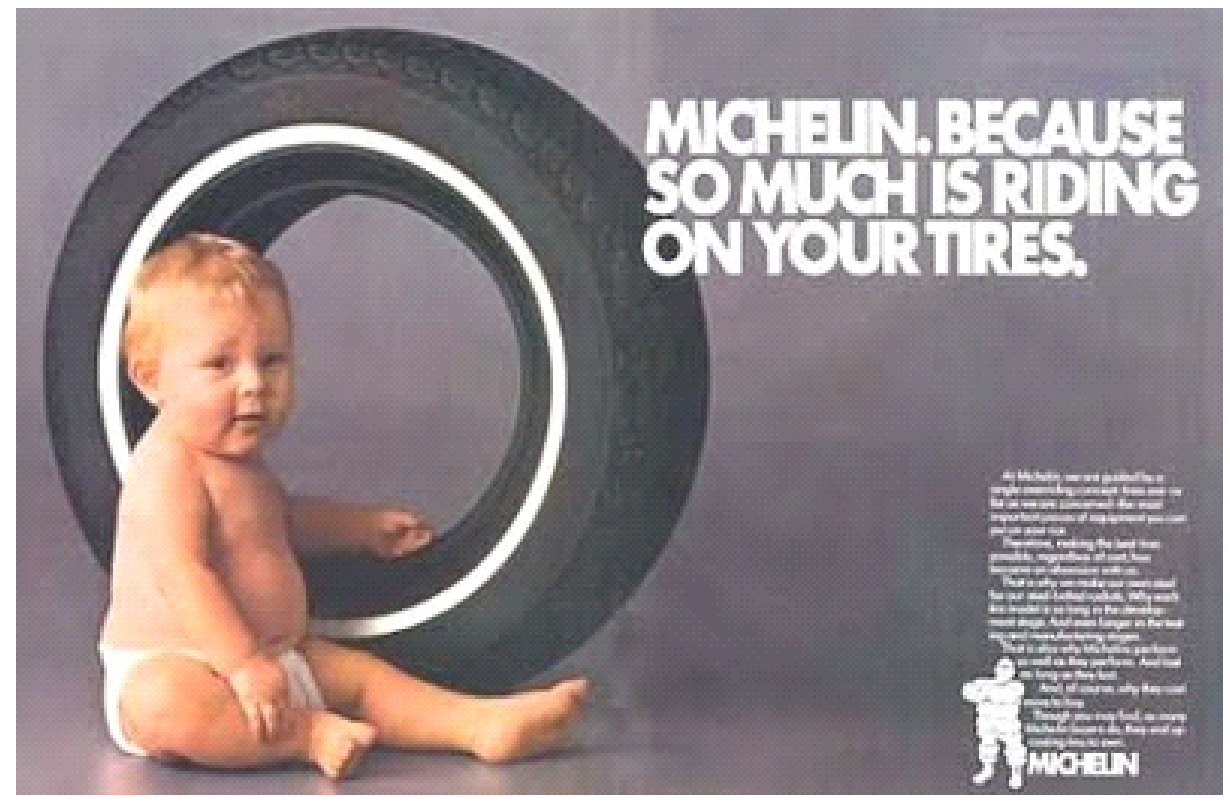

Figure 5. Michelin ad: a baby sitting next to a tire

The poster comes from a larger advertising campaign designed for the brand in the 1980s. This one presents a baby sitting next to a car tire. The background of the advertisement is dark, which provides contrast for the bright silhouette of the baby. In the top right-hand corner, there is a slogan which says: "Michelin. Because so much is riding on your tires", and below it there is a body of text in small font, explaining briefly the main idea of the advertisement, followed by the Michelin logo. The organization of the elements in the picture attempts at a visual blend.

The input spaces are, on the one hand, the BABY space and, on the other, CAR DRIVING, evoked metonymically via the image of the tire. Although tires are the object of the advertisement, putting one in the background of the picture seems not enough for the viewer to arrive at the car driving scenario, especially when there seems to be no interaction between the baby and the tire itself: both just stay there. Contrary to the situation hinted at by the anchoring slogan [“(...) so much is riding on your tires"], the situation in the picture is static, hence no scenario of motion is evoked directly. Although the input spaces are not readily recognizable and the counterpart mappings seem difficult to establish, the two inputs seem to share one generic idea, i.e. the notion of safety. What is curious is that the viewer is able to arrive at it only after several attempts are performed at composing the two elements into one picture and completing it further with the background knowledge of the car-driving conceptual frame: people generally need their children to feel safe and they themselves need to feel safe while driving. This conclusion may give rise to an emergent scenario which seems to be the intended meaning of the advertisement: the only way to provide safety for ourselves and our family, considered the greatest value in our lives, is having our car equipped with Michelin tires. This inference might be, however, questioned: proper tires evidently are important, but are they really the key factor for providing full safety while driving? 
Clearly, the blend composed for this advertisement requires a lot of cognitive effort to establish its internal elements and mappings. The emergent structure does not appear effortlessly, but on the contrary, the viewer following the principle of Relevance (see Fauconnier and Turner 1998: 340) seems forced to find the emergent meaning, which seems slightly farfetched. The judgments about Michelin tires, though, are drawn thanks to merging two highly distinctive elements into one picture, resulting in cause and effect compression.

The image of a child used in this advertisement is based on the general associations people have of children: their vulnerability and dependence on others. It seems, however, to be rather poorly incorporated within the visual representation of the conceptual idea behind the advertisement. The baby in the picture does not indicate any relation with the tire positioned behind him. The persuasive effect of the poster would be achieved with less effort if there were some interaction between the two elements, for instance, if the baby were shown playing with the tire, imitating his parents driving a car. What seems to be crucial is that it is not enough merely to insert an image of a child into an advertisement to achieve its intended goal. Instead, skillful manipulation of the element is the key. Thus, in order to advertise a product in an attractive and efficient way, it is important to manipulate it aptly on the conceptual level.

Although this particular poster does not use conceptual blending and the image of a child effectively, the whole Michelin advertising campaign, composed not only of posters but also of television commercials involving actual active integration between children and the Michelin tires, proved to be a huge success in the advertising world, providing the company with recognition and high stock ratings. Although being a part of a bigger campaign and potentially serving as a remainder of one, the poster analyzed in isolation does not achieve persuasive effects on its own but strongly depends on its larger context.

\section{Summary}

The aim of this study was to analyze the role of the emergent structure in the conceptual integration networks as employed in advertising campaigns using images of children in achieving particular persuasive effects. The first part explained Conceptual Blending Theory, focusing specifically on the creation and role of the emergent structure, as well as the process of compression, which facilitates achieving the fundamental purpose of blending, i.e. achieving human scale, as well as, in more creative uses of integration networks, providing persuasive effects. It was stressed that the emergent structure arises as a result of projections of elements from input mental spaces to form a new structure within the integration networks, the blend. What was emphasized was the fact that this newly formed mental space is composed of the elements mapped from the inputs, but also it contains elements and relations not originating in any of the mental spaces involved in the process. As a result, new inferences arise in the conceptual networks, which are later used to reevaluate the elements in the inputs via multidirectional mappings. This process, backward projection, facilitates achieving the main purpose of the blend formation, that is providing global insight and human scale for the diffused notions. It is also efficient as a potential mechanism of persuasion. 
What is also important about blending is the local and automatic character of the process, i.e. it happens immediately after exposure to the input material, and once the inferences or the reevaluation of the concepts involved are reached, the blend is decomposed in the mind of the conceptualizer, leaving him/her with new judgments and opinions about the relevant notion.

The second part focused on the analysis of the conceptual networks based on the visual input of four advertisements using an image of a child in order to achieve their persuasive effects. Each of the blends presented in the advertising posters developed their own unique emergent structure, where the image of a child played the key role in the evaluation of the advertised products. Four advertisements were analyzed, each coming from a larger advertising campaign. The first three examples provided a readily available coherent emergent structure, whereas in the fourth one the emergent structure was slightly difficult to establish due to the inconsistent structure of the mappings in the integration network. The analysis proved that in order for the blend to achieve its persuasive goals, it is crucial that it develops a well-organized and congruent emergent structure. In order to do that, the elements chosen for the creation of the blend must allow for coherent projections and form a structure which would be more than just a sum of the inputs. What is more, the construction of the emergent structure must be immediate and effortless for the arrival at coherent inferences and conclusions leading to persuasive effects.

The emergent image of a child which was developed in the blends had a significant impact on the evaluation of the advertised products. The first poster equipped the image of the girl with features strongly associated with the adults' view of the world, and juxtaposed the very positive cultural image of a child with a strongly negative side of human existence, which rendered the blend immensely powerful. The second poster emphasized the positive associations connected with children and projected them onto promoting adoption. The third advertisement presented a counterfactual image of a newborn baby already equipped with rich life-experience and used it to promote a notion not directly associated children. The forth advertisement used an image of a child least creatively of all the examples, i.e. the baby's role was only to evoke the domain of children, but the emergent structure was not effortless to establish and hence rendered the blend diffuse. In all of the posters, though, the image of a child was used to project associations typically characteristic of children onto the advertised products, which was to result in an emotional response on the part of the viewers.

In all of the advertising posters an image of a child was used which was later developed by the, stronger or weaker, emergent structure of the blends. It turned out that the blends which were able to form an effortless and immediate emergent structure provided a very vivid image of the child, which was later projected onto the advertised product. As a result, the advertisement was successful in achieving its persuasive goals by forcing the conceptualizer to project onto the advertised product the intensive feelings normally expressed towards children. In the case of the blend where the emergent structure was developed incoherently, the image of the child was static and rendered the advertisement less successful. 
To conclude, conceptual integration is a very prominent mechanism for achieving conceptual persuasion. A well-developed emergent structure is the key step in forming a coherent and internally consistent blend. For achieving the most effective integration networks it is not enough to choose juxtaposing notions and blend them together. Instead, skillful manipulation of these elements is even more crucial.

\section{References}

Brandt, Line and Per Aage Brandt. 2005. Making sense of a blend: A cognitive semiotic approach to metaphor. Annual Review of Cognitive Linguistics 3, 216-249.

Evans, Vyvyan and Melanie Green. 2006. Cognitive Linguistics: An Introduction. Edinburgh: Edinburgh University Press.

Fauconnier, Gilles. 2005. Compression and emergent structure. Language and Linguistics 6(4), 523-538.

Fauconnier, Gilles and Mark Turner. 1995. Conceptual integration and formal expression. Metaphor and Symbolic Activity 10(3), 183-203.

Fauconnier, Gilles and Mark Turner. 1998. Conceptual integration networks. In: Geeraerts, Dirk (ed.), Cognitive Linguistics: Basic Readings, 303-371. Berlin/New York: Mouton de Gruyter.

Fauconnier, Gilles and Mark Turner. 2000. Compression and global insight. Cognitive Linguistics 11(3/4), 283-304.

Fauconnier, Gilles and Mark Turner. 2002. Conceptual Blending and the Mind's Hidden Complexities. New York: Basic Books.

Forceville, Charles. 1994. Pictorial metaphor in advertisements. Metaphor and Symbolic Activity 9, 1-29. Joy, Annamma, Sherry John F. and Jonathan Deschenesa. 2009. Conceptual blending in advertising. Journal of Business Research 62, 39-49.

Kövecses, Zoltán. 2006. Language, Mind, and Culture: A Practical Introduction. Oxford: Oxford University Press.

Turner, Mark. 2006. Compression and representation. Language and Literature 15(1), 17-27. http://7 ssrn.com/abstract=1672132 (22 March 2013)

Turner, Mark. 2007. Frame Blending. In: Rossini Favretti, Rema (ed.), Frames, Corpora, and Knowledge Representation, 13-32. Bologna: Bononia University Press. http://ssrn.com/7 abstract=1321302 (22 March 2013)

\section{List of figures}

Figure 1 Mechanism of blending, http://markturner.org/blending.html (10 October 2012)

Figure 2 http://adsoftheworld.com/media/print/chupa_chups_jumper (10 October 2012)

Figure 3 http://adsoftheworld.com/media/print/the_indian_association_for_promotion _of_adoption_child_welfare_mother_daughter (11 October 2012)

Figure 4 http://adsoftheworld.com/media/print/sofia_bank_baby_1 (10 October 2012) Figure 5 http://www.startupnation.com/images/pages/articles/12-3-28-Branding-article/ Michelin02.jpg (10 October 2012) 